\title{
Review Article \\ Review on Techniques for On-Line Monitoring of Resistance Spot Welding Process
}

\author{
Yanhua Ma, Pei Wu, Chuanzhong Xuan, Yongan Zhang, and He Su \\ College of Mechanical and Electrical Engineering, Inner Mongolia Agricultural University, Hohhot 010018, China \\ Correspondence should be addressed to Pei Wu; jdwupei@163.com
}

Received 2 August 2013; Accepted 26 November 2013

Academic Editor: Daolun Chen

Copyright (C) 2013 Yanhua Ma et al. This is an open access article distributed under the Creative Commons Attribution License, which permits unrestricted use, distribution, and reproduction in any medium, provided the original work is properly cited.

\begin{abstract}
Resistance spot welding has been widely used for joining sheet metals, especially in automotive and aerospace industries. However, since the formation of weld nugget is invisible in resistance spot welding, traditionally off-line destructive test is applied for inspection of the weld quality, which is costly and inefficient. Therefore, in recent years, a lot of efforts have been made in estimating or detecting the weld quality nondestructively by on-line welding parameter monitoring. This paper presents a review on techniques of monitoring resistance spot welding process or weld quality, and the advantages as well as limitations of these techniques are discussed.
\end{abstract}

\section{Introduction}

Resistance spot welding (RSW) is widely used for joining sheet metals and is recognized as the most rapid and economic joining method, its unique advantages have kept it as one of the most productive and competitive joining technologies in automotive, aerospace, and other metal processing industries [1-4]. However, due to the fact that the welding time is short and the weld nugget (as shown in Figure 1) is formed inside the workpiece in resistance spot welding, which is invisible and the weld quality can not be assessed by simply observing the nugget, destructive test and such as peel test, shear test, traditionally has to be used for inspection of the weld quality, which is unsatisfactory:

(1) wasteful of time and materials;

(2) if the test reveals a defect, all the components welded since the last test may have to be scrapped;

(3) since the inspection is on sampling basis, it cannot be guaranteed that all the welds in the accepted lot are defect-free;

(4) difference between poor and good weld is not visible to naked eye.
In addition there is a large number of interrelated variables in resistance welding; weld quality is extremely operation dependent and varied from part to part due to such changes as workpiece surface condition, electrode tip fit-up, circuit impedance, shunt effect, and so forth Therefore, in recent years, a lot of efforts have been made in estimating or detecting the weld quality nondestructively by on-line welding parameter monitoring or on-line visual inspection of the welding spot, which is especially beneficial to the continuous production of automated system as the faults may be immediately identified and rectified $[5,6]$.

The principle of in-process monitoring and weld quality control is monitoring some phenomena or characteristics which occurs or changes during the formation of the nugget. Although in-process weld quality monitoring or control is still not universally proved, it is certainly the ideal and promising approach $[7,8]$. In this paper, a comprehensive review on monitoring resistance spot welding process or weld quality is presented.

\section{By On-Line Welding Parameter Monitoring}

Actually, the process of resistance spot welding is complicated, involving mechanical, electrical, thermal, and metallurgical problems, due to the large number of interrelated 


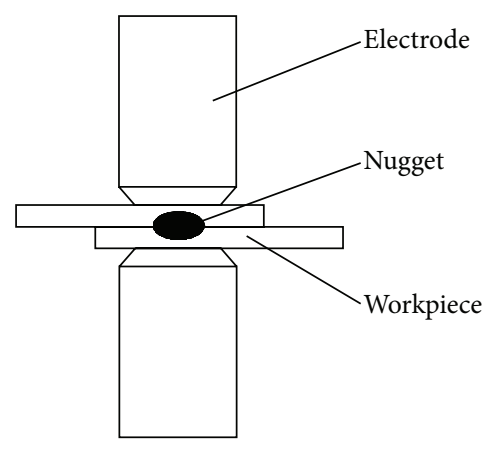

FIgURE 1: Resistance spot welding.

variables. Normally, the parameters monitored for weld quality detection are classified into two types: one is the parameters related to the power input (e.g., welding current, electrode tip voltage, or dynamic resistance) of the welding process and the other is the one related to mechanical response, such as dynamic electrode displacement, applied electrode force and acoustic emission.

2.1. Monitoring the Welding Parameters Related to Power Input. The power or heat source is closely correlated to the nugget formation; the parameters measured for monitoring the welding process or weld quality include welding current and tip voltage between electrodes, but normally they are not directly used and the dynamic resistance or energy obtained based on them is used instead.

2.1.1. Dynamic Resistance. Dynamic resistance is computed based on the instantaneous value of electrode tip voltage divided by the corresponding welding current at that moment. For the resistance welding with AC power, the peak values of tip voltage and welding current are used for computing the dynamic electrode resistance in order to reduce the effect of electromagnets [9-17]. Gedeon et al. [18] in 1987 improved the accuracy of resistance estimation by representing each half cycle of the voltage and current with a curved line. In recent years, Cho and Rhee [19-21] proposed that dynamic resistance could be obtained from the primary circuit and voltage instead of secondary circuit and voltage because the primary voltage and current can be measured much more easily compared to the other methods mentioned earlier.

A typical curve of time variation in dynamic resistance for welding different materials is presented in Figure 2 [9]. It can be seen that each metal or alloy has its typical pattern of dynamic resistance curve, but only the one of the dynamic resistance curve for mild steel has apparent features correlated with nugget growth and provides a means of monitoring weld quality. The curve for mild steel can be clearly identified in three regions: region I where the resistance has a sharp drop corresponding to the breakdown of contact insulation in the beginning of current input; region II where there is increasing dynamic resistance owing to the increase of temperature of work piece; region III where there is decreasing dynamic resistance as the growth of the fused

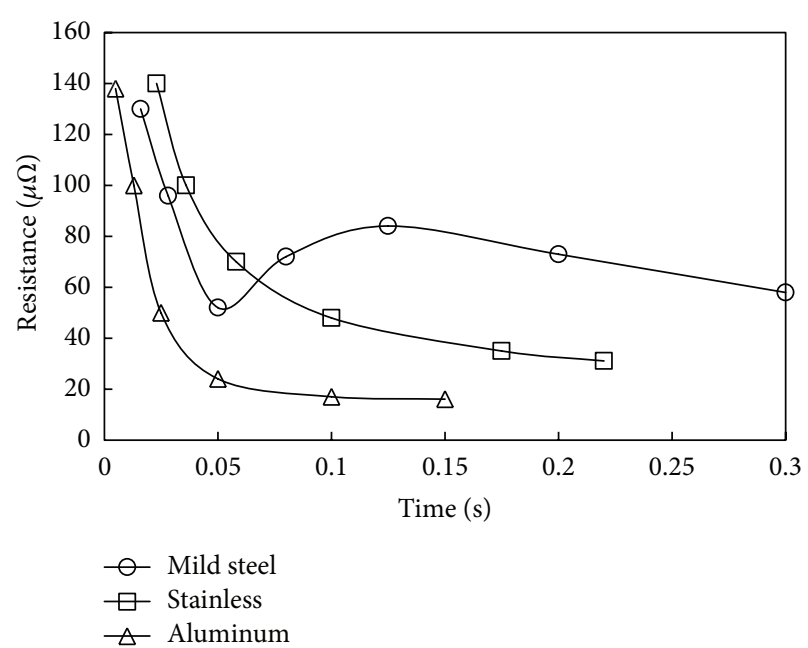

FIGURE 2: A typical curve of dynamic resistance for welding different materials.

metallic bond; The fall in resistance will be more abrupt if metal splash takes place. Comparable correlation in stainless steel and aluminum is made difficult by the very nature of the curves, and it provides insufficient information for monitoring weld quality.

The dynamic resistance is therefore a good method for the monitoring conditions of welding processes and developing faults of the welds for mild steel. However, its major drawback is the accuracy of the dynamic resistance as a function of time. The time-record is highly discontinuous as it is actually performed at a single moment belonging to every half cycle. More recently, input impedance has been used as a signature for monitoring the resistance welding process $[22,23]$.

An advantage of dynamic resistance methods is that they do not require the use of complicated sensors for measurement of relevant electrical parameters, and they permit straightforward implementation of real-time systems for controlling the quality of each welded spot.

2.1.2. Input Impedance. A resistance spot welding machine is equivalent to an electrical circuit consisting of resistance $(R)$, inductance $(L)$, and capacitance $(C)$ in series as shown in Figure 3. The input impedance of this electrical system is defined as the quotient between the excitation voltage and response current at the input port, which is a function of the system parameters $R, L$, and $C$ and appears as a complex number depending on frequency. The real part represents the resistance and the imaginary part and the reactance of the electrical circuit. The input impedance characterizes the equivalent circuit of a welding system independent of the excitations. For a RSW system, however, the parameters, particularly the resistance, change dramatically by the successive phases of heating, melting, fusion, and solidification during a welding period. The real part and imaginary part of its input impedance appear therefore as two time-domain records. The patterns of these two time records directly represent the varying conditions of welding process point by point and indirectly reflect the resulting weld quality. 


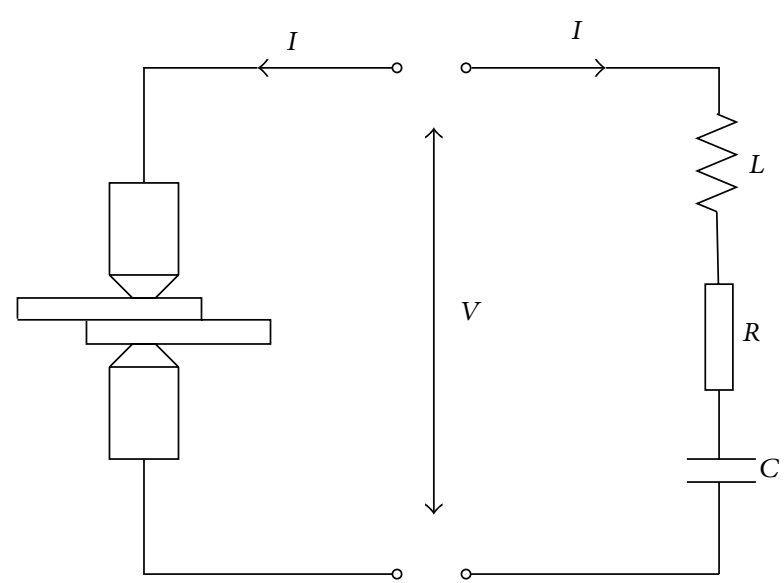

FIgURe 3: Equivalent $R L C$ circuit.

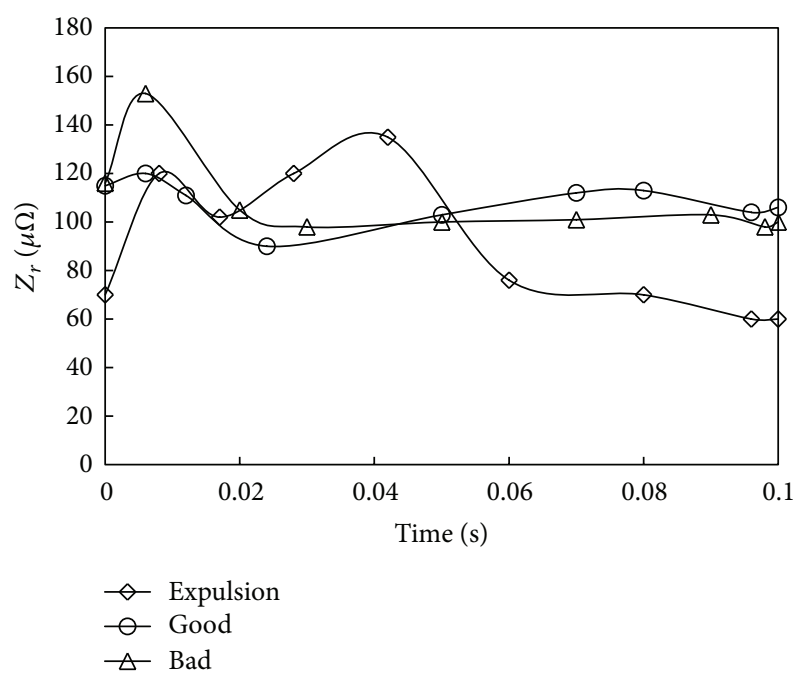

FIGURE 4: $Z_{r}(t)$ of a typical resistance spot welding process.

The input electrical impedance $Z_{\text {in }}$ can be expressed as

$$
\begin{gathered}
Z_{\text {in }}(t)=\frac{v(t)}{i(t)}=\left|Z_{\text {in }}(t)\right| e^{j \varphi(t)} \\
Z_{\text {in }}(t)=Z_{r}(t)+j \omega Z_{x}(t) .
\end{gathered}
$$

In the above equations, $v(t)$ and $i(t)$ are the analytical signals of real voltage and current signal, respectively. The amplitude $\left|Z_{\text {in }}(t)\right|$ and the phase $\varphi(t)$ of the impedance $Z_{\text {in }}(t)$ represent the amplitude ratio and the phase between the input voltage and input current signal, respectively. The real part $Z_{r}(t)$ and imaginary part $Z_{x}(t)$ of $Z_{\text {in }}(t)$ are actually the resistance and reactance of the equivalent circuit.

Figure 4 shows $Z_{r}(t)$ of resistance spot welding processes creating good and bad welds when welding low carbon steel plates (specimens: two plates are welded, for each with size of $150 \times 70 \times 0.5 \mathrm{~mm}$, welding parameters: current time $0.1 \mathrm{~s}$, electrode force $1.35 \mathrm{kN}$, welding current $4.5 \sim 8.0 \mathrm{kA}$ ) [22].

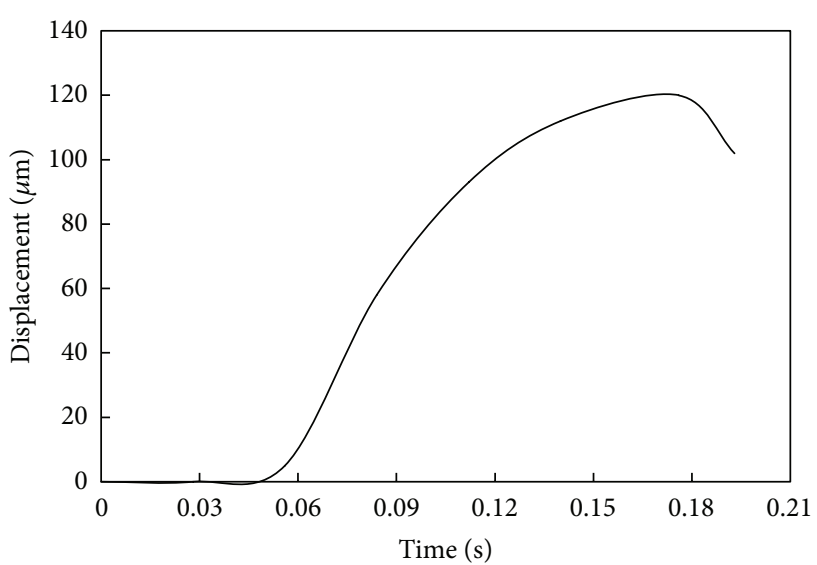

FIgURE 5: Ideal displacement curve.

The waveform of $Z_{r}(t)$ reveals that the variation of the electrical resistance appeared during a welding process. From Figure 4 , it can be seen that the patterns of $Z_{r}(t)$ curves have apparent features under the different weld qualities. Typically when the weld is good, the resistance increases at the beginning until the first peak where the asperity surface is broken down at the faying surface. It then reduces dramatically to the trough and starts to increase again gradually until the second peak due to the increase of temperature. The second peak roughly implies that the weld nugget grows to its desired size.

\subsection{Monitoring the Welding Parameters Related to Mechanical Response}

2.2.1. Electrode Displacement. Electrode displacement has been proven to be a useful signal to monitor the welding quality because it gives a good indication of thermal expansion, melting, and expulsion during resistance spot welding [2428]. A typical trace of the electrode displacement of welding mild steel when the weld is good is shown in Figure 5 [26].

At the beginning the displacement is very small due to the small thermal expansion, and then it rapidly rises with the increase of heat input. The peak of displacement waveform corresponds to the maximum expansion which occurs at termination of welding current. When current ceases, the electrode displacement starts to fall owing to cooling. When heat input is not enough to form an ideal nugget (e.g., the welding current is too low), the thermal expansion is smaller; thus the electrode displacement is lower compared to that when the weld is good. When expulsion occurs, the electrode displacement has a sudden fall since the electrode loses contact at the moment and the electrode rapidly moves to another (as shown in Figure 6) [26]. So the pattern of the electrode displacement provides good information on welding process and is a good signature for weld quality monitoring purpose. However, the problem is that normally the high-precision laser displacement sensor is needed because the electrode displacement is small and easy to be contaminated by electromagnetic noise, and the laser transducer is more expensive. 


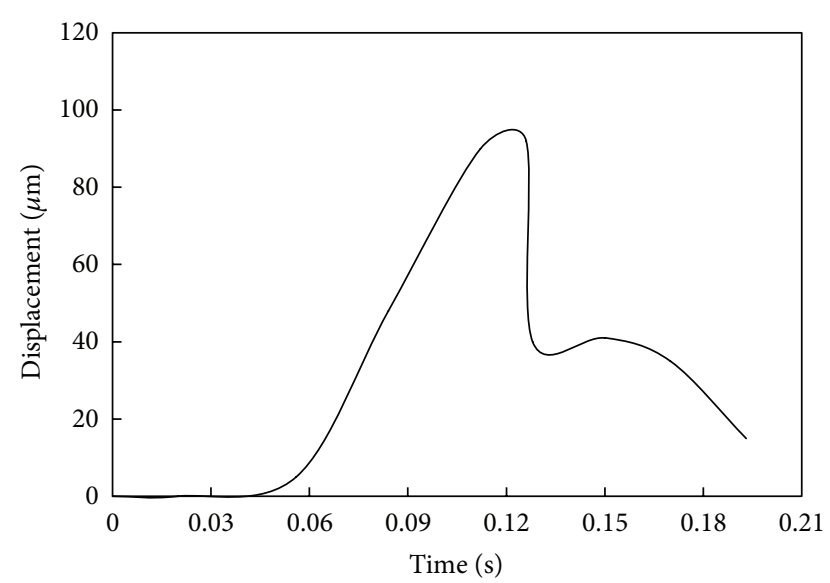

Figure 6: Expulsion displacement curve.

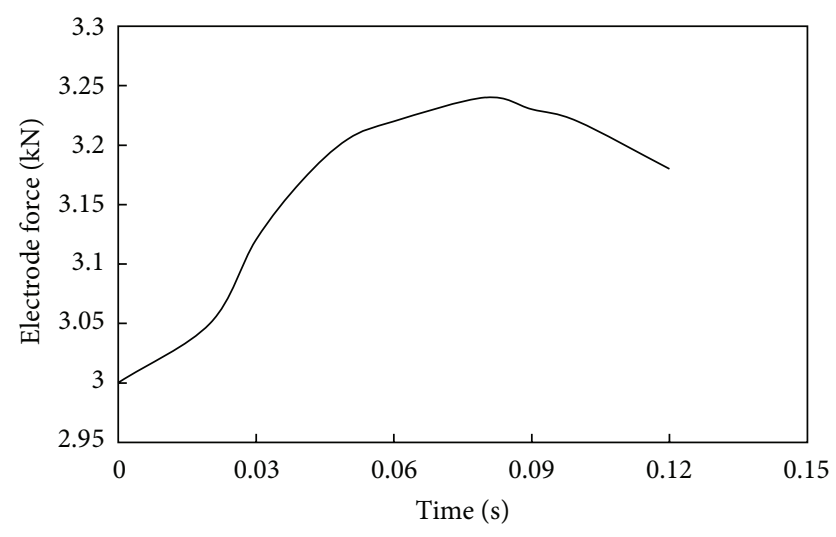

FIGURE 7: Typical electrode force curve when welding stainless steel.

2.2.2. Electrode Force. In resistance spot welding the electrode force is applied to squeeze the metal sheets to be joined together. The required electrode force must overcome distort of the material so that the sheet metals to be welded at the weld zone have an intimate contact before welding current flow. However, the force must not be too large as it might cause other problems, such as indentation of the metal. During a resistance spot weld, the electrode force exerted on the material is dynamic and closely related to the contact resistance at faying surface. When the electrode force is increased the contact resistance will decrease and thus the heat energy will decrease. This means that a higher electrode force requires a higher weld current [29-31].

A typical electrode force curve of stainless steel at preset value of $3.0 \mathrm{kN}$ during welding is shown in Figure 7. It can be seen that the actual force during welding stage is greater than the preset one $(3.0 \mathrm{kN})$; it increases rapidly at the beginning of welding current application, and then the force reaches its maximum value before the current terminates. The basic reason for the force increase is the thermal expansion of the weld nugget due to Joule heating, which makes the electrode tips apart. After a certain welding time, as the further heat input, the electrode force begins to drop when the weld zone

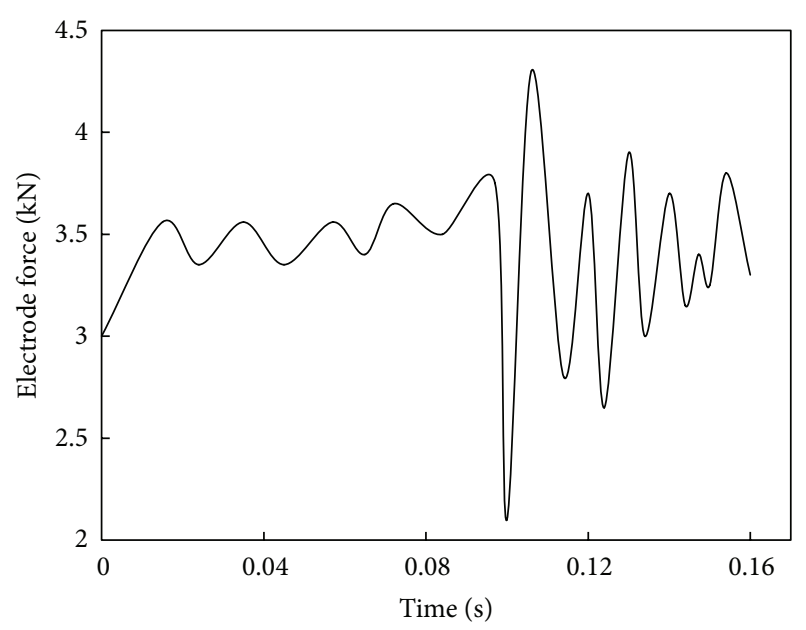

Figure 8: Typical electrode force curve with expulsion.

softens and has less resistance to electrode squeezing at high temperature [15].

Figure 8 is the electrode force curve of welding stainless steel with expulsion [29]. It clearly reveals that the electrode force suddenly drops and subsequently has a sharp increase again and then up and down with a fluctuation. This is because, when an expulsion happens, the electrode will suddenly move into another and collide on the part due to the loss of support, and an impact will be excited.

Therefore, the electrode force indicates the welding status and can be used as a signature for monitoring the weld quality, but the drawback is that the transducer is normally more complicated and easy to be polluted by the electromagnetic force compared to the methods of dynamic resistance or electrode displacement $[11,32,33]$. In resistance spot welding, a strong magnetic field is generated due to a high current being applied, and the electromagnetic force has an effect of reducing the electrode force [34].

2.2.3. Acoustic Emission. When metal is deformed or cracked by force, it normally releases deformation energy in the form of elastic wave. If this deformation energy is big enough, it will emit audible sound. Resistance spot welding is a process coupled by heat, force and metallurgy. During the nugget formation, it will generate sound wave when the metal in welding zone has deformation and metallurgic transformation. For different welding quality, the sound wave is different, which is the principle of monitoring welding process by using structure-borne acoustic emission signals [35-38].

As an example, Figures 9 and 10 show the acoustic emission signals with resistance spot welding aluminum alloy. For the welding cases in both Figures 9 and 10, the specimen is two-layer aluminum alloy plates with size of $25 \times$ $100 \times 2 \mathrm{~mm}$; the welding current is $24 \mathrm{kA}$ and current duration is $0.16 \mathrm{~s}$, but the electrode pressure force is $0.1 \mathrm{MPa}$ for the weld in Figure 9, and $0.28 \mathrm{MPa}$ for Figure 10 [37]. It can be found that the stage features presented by the sound signals in welding process are distinguished, including the electrode 


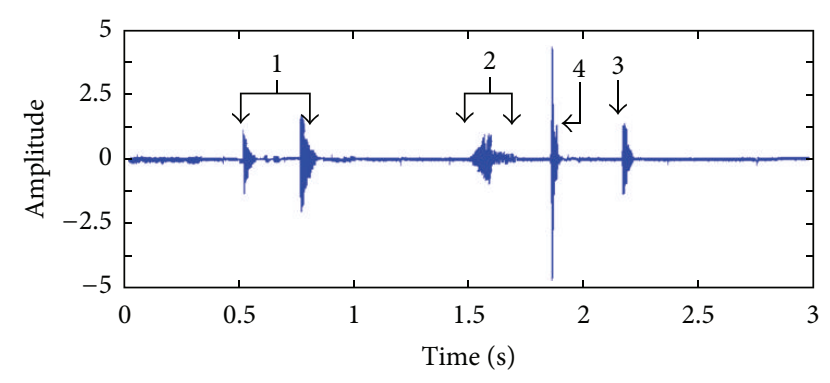

FIgURE 9: Typical acoustic emission signal with cracking.

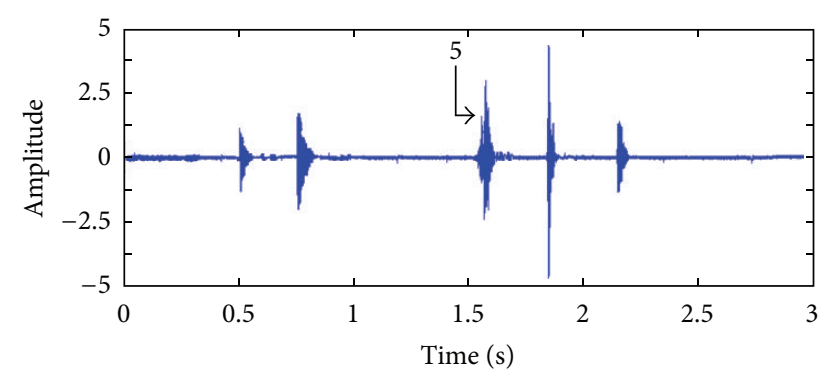

FIgURE 10: Typical acoustic emission signal with expulsion.

loading event (arrow 1 in Figure 9), nugget nucleation event (arrow 2 in Figure 9), electrode unloading event (arrow 3 in Figure 9) and cracking event (arrow 4 in Figure 9). The expulsion event is indicated as arrow 5 in Figure 10.

\section{Discussions}

Resistance spot welding is a process coupling the mechanical, electrical, thermal, and metallurgical problems. Therefore, the weld quality can be monitored by detecting the process variables correlated to these problems, and these variables are divided into two types: one is the parameters related to the power input and the other is the one related to mechanical response during the welding process.

The power input is the heat source which is directly reflected by welding current and tip voltage between electrodes; normally they are not used directly but the dynamic resistance obtained by them is used for monitoring the welding process. The dynamic resistance is a very good parameter for monitoring the welding process for mild steel, but it has some problems in working with stainless steel and aluminum. Since the signal of tip voltage between electrodes is relatively small and the measuring leads have an interruption to the movement of electrode, some researchers suggested measuring the process variables in primary circuit of the welding machine and obtained the variation of the dynamic resistance across electrodes. A similar method is that the dynamic resistance is obtained by the real part of impedance calculated based on the primary current and voltage.

The parameters concerning the mechanical response during resistance spot welding include electrode displacement, electrode force, and acoustic emission. Displacement monitoring has been shown to provide the most reliable indication of spot weld quality through weld expansion measurements no matter what materials are welded; however, this approach is less applicable to flexible equipment such as welding guns in production. Electrode force waveform especially the relationship between force peak and its subsequent force drop is the basis for monitoring the formation of the weld nugget; the problem is that it is less likely to be continuously monitored and easy to be affected by electromagnetic force. Acoustic emission can characterize the resistance spot welding process, and the challenge is that the signal is likely to be contaminated by noise and a sophisticated signal processing method is needed to abstract the features for monitoring the welding process.

\section{References}

[1] RWMA, Resistance Welding Manual, Resistance Welder Manufacturer's Association, Philadelphia, Pennsylvania, 4th edition, 1989.

[2] A. Stiebel, C. Ulmer, D. Kodrack, and B. Holmes, "Monitoring and control of spot weld operations," SAE Technical Paper 860579, International Congress and Exposition, Detroit, Michigan, 1986.

[3] S. A. Westgate, "Resistance welding-state of the art," Welding and Cutting, vol. 55, no. 5, pp. 256-260, 2003.

[4] S. A. Westgate, "A general overview of recent developments in resistance welding," in Proceedings of the 2 nd International Seminar on Advances in Resistance Welding, Aachen, Germany, 2002.

[5] D. W. Dickinson, J. E. Franklin, and A. Stanya, "Characterization of spot welding behavior by dynamic electrical parameter monitoring," Welding Journal, vol. 59, no. 6, pp. 170-176, 1980.

[6] J. Ruisz, J. Biber, and M. Loipetsberger, "Quality evaluation in resistance spot welding by analysing the weld fingerprint on metal bands by computer vision," International Journal of $A d v$ anced Manufacturing Technology, vol. 33, no. 9-10, pp. 952-960, 2007.

[7] Y. V. Kamat and K. D. Lagoo, "In-process monitoring of resistance spot welding," Measurement Technology and Intelligent Instruments, vol. 2101, no. 1, pp. 650-659, 1993.

[8] T. Kim, Y. Lee, J. Lee, and S. Rhee, "A study of nondestructive weld quality inspection and estimation during resistance spot welding," in Advances in Nondestructive Evaluation, vol. 270273 of Key Engineering Materials, pp. 2338-2344.

[9] D. R. Andrews and S. Bhattacharya, "Dynamic resistance and its application to in-process control of spot welding," Exploiting Welding in Production Technology, no. 1, pp. 221-227, 1975.

[10] C. S. Chien and E. Kannatey-Asibu, "Investigation of monitoring systems for resistance spot welding," Welding Journal, vol. 81, no. 9, pp. 195s-199s, 2002.

[11] A. G. Livshits, "Universal quality assurance method for resistance spot welding based on dynamic resistance," Welding Journal, vol. 76, no. 9, pp. 383s-390s, 1997.

[12] X. Chen and K. Araki, "Fuzzy adaptive process control of resistance spot welding with a current reference model," in Proceedings of the IEEE International Conference on Intelligent Processing Systems, pp. 190-194, Beijing, China, 1997.

[13] X. Wang, G. Meng, Y. Li, W. Xie, and Z. Feng, "Measurement of primary dynamic resistance of AC resistance spot welding using 
power factor and piecewise spline interpolation," Advanced Science Letters, vol. 4, no. 6-7, pp. 1939-1944, 2011.

[14] J. Wen, C. S. Wang, G. C. Xu, and X. Q. Zhang, "Real time monitoring weld quality of resistance spot welding for stainless steel," ISIJ International, vol. 49, no. 4, pp. 553-556, 2009.

[15] G. Xu, J. Wen, C. Wang, and X. Zhang, "Quality monitoring for resistance spot welding using dynamic signals," in Proceedings of the IEEE International Conference on Mechatronics and Automation (ICMA' 09), pp. 2495-2499, Changchun, China, 2009.

[16] S. C. Wang and P. S. Wei, "Modeling dynamic electrical resistance during resistance spot welding," Journal of Heat Transfer, vol. 123, no. 3, pp. 576-585, 2000.

[17] F. Garza and M. Das, "On real time monitoring and control of resistance spot welds using dynamic-DC resistance signatures," in Proceedings of the 44th IEEE Midwest Symposium on Circuits and Systems, vol. 1, pp. 41-44, 2001.

[18] S. A. Gedeon, C. D. Ulrich, K. T. Ululrich, and T. W. Eager, "Measurement of dynamic electrical and mechanical properties of resistance spot welds," Welding Journal, vol. 66, no. 6, pp. 378s-385s, 1987.

[19] Y. Cho and S. Rhee, "New technology for measuring dynamic resistance and estimating strength in resistance spot welding," Measurement Science \& Technology, vol. 11, no. 8, pp. 1173-1178, 2000.

[20] Y. Cho and S. Rhee, "Primary circuit dynamic resistance monitoring and its application to quality estimation during resistance spot welding," Welding Journal, vol. 81, no. 6, pp. 40-43, 2002.

[21] Y. Cho, Y. Kim, and S. Rhee, "Development of a quality estimation model using multivariate analysis during resistance spot welding," Proceedings of the Institution of Mechanical Engineers, Part B: Journal of Engineering Manufacture, vol. 215, no. 11, pp. 1529-1538, 2001.

[22] S.-F. Ling, L.-X. Wan, Y.-R. Wong, and D.-N. Li, "Input electrical impedance as quality monitoring signature for characterizing resistance spot welding," NDT \& E International, vol. 43, no. 6, pp. 200-205, 2010.

[23] S. F. Ling and L. X. Wan, "Monitoring a spot welding process via electrical input impedance," in Proceeding of the 19th International Conference on Experimental Mechanics, pp. 348$351,2000$.

[24] D. Hu, R. Zheng, and D. Ji, "Study of electrodes displacements monitoring system in resistance spot welding," Journal of Nanchang Institue of Aeronautical Technology China, no. 1, pp. 16-22 (Chinese).

[25] H. S. Cho and D. W. Chun, "A microprocessor-based electrode movement controller for spot weld quality assurance," IEEE Transactions on Industrial Electronics, vol. 32, no. 3, pp. 234-238, 1985.

[26] H. Wang, Y. Zhang, and A. Chen, "Resistance spot welding processing monitoring based on electrode displacement curve using moving range chart," Measurement, vol. 42, no. 7, pp. 10321038, 2009.

[27] Y. S. Zhang, X. Y. Zhang, X. M. Lai, and G. L. Chen, "Online quality inspection of resistance spot welded joint based on electrode indentation using servo gun," Science and Technology of Welding and Joining, vol. 12, no. 5, pp. 449-454, 2007.

[28] Y. Li, J. Xu, G. Chen, and Z. Lin, "Real-time measuring system design and application of thermal expansion displacement during resistance spot welding process," Proceedings of the Society of Photo-Optical Instrumentation Engineers, vol. 6041, pp. T411T411, 2005.
[29] Y. J. Park and H. Cho, "Quality evaluation by classification of electrode force patterns in the resistance spot welding process using neural networks," Proceedings of the Institution of Mechanical Engineers B, vol. 218, no. 11, pp. 1513-1524, 2004.

[30] C. Ma, S. D. Bhole, D. L. Chen, A. Lee, E. Biro, and G. Boudreau, "Expulsion monitoring in spot welded advanced high strength automotive steels," Science and Technology of Welding and Joining, vol. 11, no. 4, pp. 480-487, 2006.

[31] C. T. Ji and Y. Zhou, "Dynamic electrode force and displacement in resistance spot welding of aluminum," Journal of Manufacturing Science and Engineering, vol. 126, no. 3, pp. 605-610, 2004.

[32] R. B. Hirsch, “Tip force control equals spot weld quality," Welding Journal, vol. 72, no. 2, pp. 57-60, 1993.

[33] H. Tang, W. Wu, S. J. Hu, and H. Zhang, "Force characteristics in resistance spot welding," Welding Journal, vol. 79, no. 7, pp. 175s183 s, 2000.

[34] P. Wu, Y. H. Ma, B. S. Han, and J. Y. Han, "Experiment and analysis on electromagnetic force in resistance spot welding," Transaction of Welding, vol. 27, no. 10, pp. 4-6, 2006 (Chinese).

[35] S. I. Rocklin and L. Adler, "Ultra evaluation of spot welding quality," Welding Journal, vol. 64, no. 3, pp. 191-200, 1985.

[36] Z. Luo, S. Hu, and P. Shan, "Application of time frequency analysis to air borne acoustic signals of aluminum alloys spot welding," Transactions of the China Welding Institution, no. 1, pp. 3637, 2004 (Chinese).

[37] Y. luo, J. Li, and W. Wu, "Characterization of nugget nucleation quality based on the structure-borne acoustic emission signals detected during resistance spot welding process," Measurement, vol. 46, pp. 1053-1060, 2013.

[38] H.-T. Lee, M. Wang, R. Maev, and E. Maeva, "A study on using scanning acoustic microscopy and neural network techniques to evaluate the quality of resistance spot welding," International Journal of Advanced Manufacturing Technology, vol. 22, no. 9-10, pp. 727-732, 2003. 

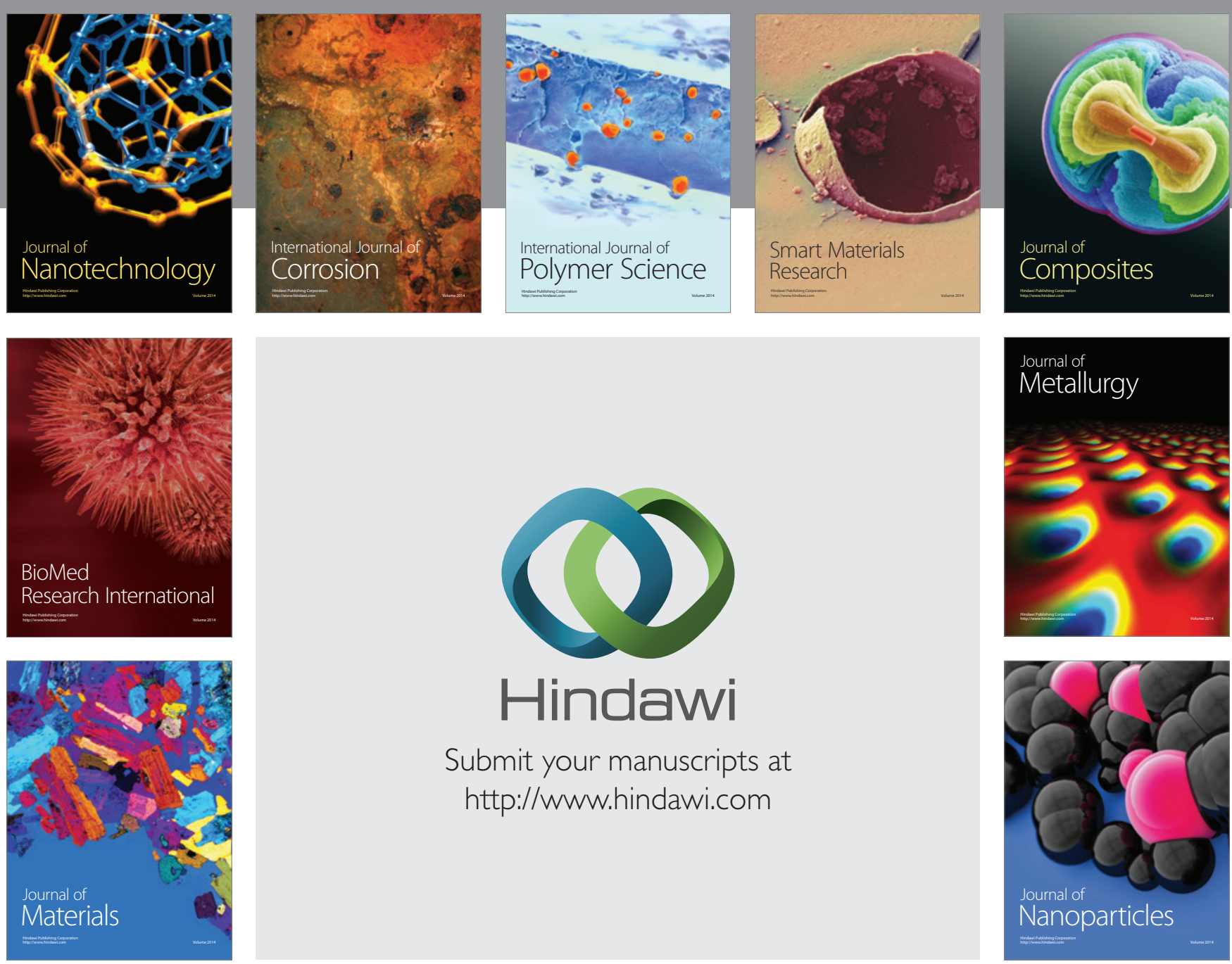

Submit your manuscripts at http://www.hindawi.com
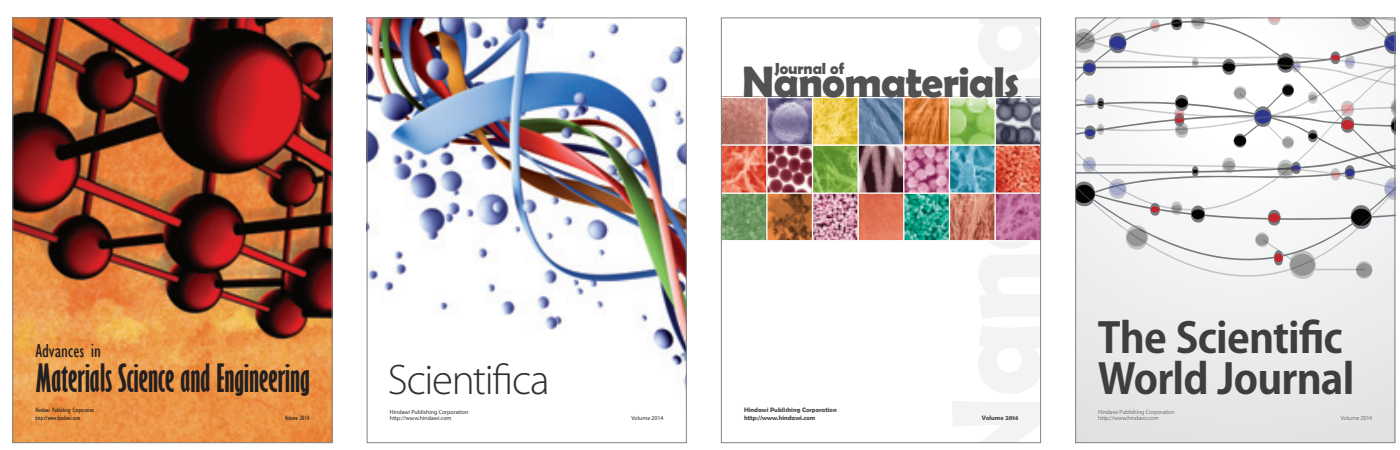

\section{The Scientific World Journal}
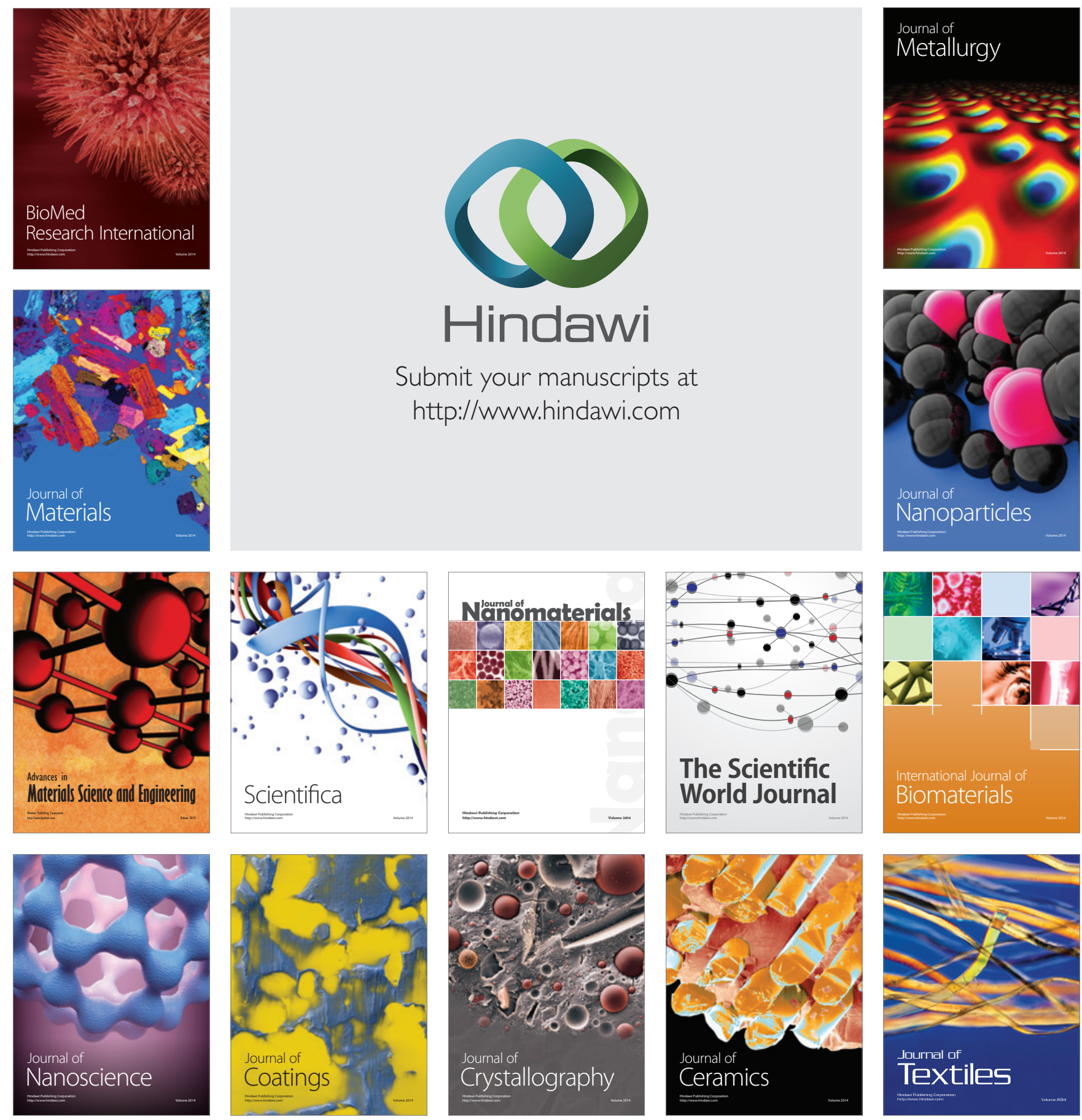